\title{
QUALIDADE DE VIDA NO TRABALHO: uma investigação em unidades da rede hoteleira na cidade de Mossoró, Rio Grande do Norte/RN, Brasil
}

\section{QUALITY OF LIFE AT WORK: an investigation in units of the hotel network in the city of Mossoró, Rio Grande do Norte / RN, Brazil}

\author{
Anuska Karina Nogueira Maia (MAIA, A. K. N.) ${ }^{*}$ e \\ Gustavo Henrique Barreto de Sousa (SOUSA, G. H. B. de.) ${ }^{* *}$
}

RESUMO - Ao longo deste trabalho buscou-se analisar a qualidade de vida no trabalho de dois hotéis da cidade de Mossoró (Rio Grande do Norte/RN, Brasil). O objetivo geral da pesquisa foi analisar a percepção dos seus dois gerentes em relação aos programas de QVT. A pesquisa de campo foi de caráter qualitativo, onde os dados foram coletados por meio de entrevistas realizadas no ano de 2016. Percebeu-se a preocupação por parte da gerência dos hotéis escolhidos de investir na qualidade de seus produtos e serviços, para proporcionar melhoria nas condições de trabalho dentro de uma relação social que possibilitasse a qualidade de vida dos empregados. Pôde-se compreender a importância da qualidade de vida no trabalho, contribuindo para o desenvolvimento pessoal, a saúde e bem estar dos funcionários. Para tanto, foi necessária uma revisão de literatura acerca de alguns conceitos e modelos de QVT, bem como, conhecimentos ligados à estruturação do setor hoteleiro em Mossoró, investigados através da pesquisa de campo. Percebeu-se existir medidas pautadas em tentativas de favorecer o colaborador de qualquer maneira possível, sem alguma condição de planejamento, mas que satisfizesse o gestor. Mesmo assim, percebeu-se que o termo QVT estava em evidência, mesmo sem estar estruturada de forma racional e planejada nas empresas pesquisadas.

Palavras-chaves: Turismo; Qualidade; Trabalho; Hotelaria.

ABSTRACT - Throughout this work, we sought to analyze the quality of life in the work of two hotels in the city of Mossoró (Rio Grande do Norte / RN, Brazil). The general objective of the research was to analyze the perception of its two managers in relation to QLT programs. The field research was qualitative, where the data were collected through interviews conducted in the year 2016. It was noticed the concern of the management of the chosen hotels to invest in the quality of their products and services, to provide improvement in the conditions of work within a social relationship that would enable employees' quality of life. It was possible to understand the importance of quality of life at work, contributing to personal development, health and well-being of employees. Therefore, it was necessary to review the literature about

\footnotetext{
Formação: Bacharel em Turismo pela Universidade do Estado do Rio Grande do Norte (UERN), Especialização em Gestão Estratégica de Pessoas e Liderança Organizacional pela Faculdade do Vale do Jaguaribe (FVJ). Estudante do curso de Administração na Universidade Federal Rural do Semi-Árido (UFERSA). Endereço físico para correspondência: Rua Agrônomo Assis Reinaldo, 1449. CEP: 59633210 - Mossoró-RN - Brasil. E-mail: anuska_karina@hotmail.com

** Formação: Graduação em Economia pela Universidade do Estado do Rio Grande do Norte (UERN), Especialização e Mestrado em Administração pela Universidade Regional do Cariri (URCA) / Universidade Potiguar (UNP). Atividade profissional: Docente do curso de Gestão Estratégica de Pessoas e Liderança Organizacional da Faculdade do Vale do Jaguaribe (FVJ). Endereço físico para correspondência: Rua Prudente de Morais, 976. CEP: 59603-025 - Mossoró-RN - Brasil. E-mail: gustavobarreto71@ gmail.com
} 
some concepts and models of QWL, as well as knowledge related to the structuring othe hotel sector in Mossoró, investigated through field research. It was noticed that there were measures based on attempts to favor the employee in any possible way, without some condition of planning, but that satisfied the manager. Even so, it was noticed that the term QVT was in evidence, even without being structured in a rational and planned way in the companies surveyed.

Key words: Tourism; Quality; Work; Hospitality. 


\section{INTRODUÇÃO'}

O termo Qualidade de Vida no Trabalho (QVT) deve ser considerado em relação às constantes transformações nas relações de trabalho. Tais transformações vêm ocorrendo devido ao impulso dos avanços tecnológicos e organizacionais, exigindo cada vez mais qualificação dos trabalhadores no atual regime do capitalismo flexível.

É importante destacar que não existe um debate consensual em relação ao tema da QVT. Todavia, os autores que tratam sobre esse tema geralmente trazem como objeto o bem-estar do trabalhador e a melhoria nos processos laborais. Buscando sempre uma relação de equilíbrio entre os interesses do trabalhador e da organização, favorecendo mutuamente pontos positivos.

A preocupação com a QVT surgiu na década de 1950, na Inglaterra, a partir dos estudos de Eric Trist e colaboradores, do Tavistock Institute, com o objetivo de analisar a relação indivíduo-trabalho-organização. Quando foi desenvolvida uma abordagem sócio-técnica da organização do trabalho, tendo como base a satisfação do funcionário no ambiente laboral e em relação a ele. Contudo, só a partir da década de 1960, houve um novo impulso nos movimentos de QVT, com o desenvolvimento de várias pesquisas sobre melhores formas de realizar a tarefa, enfocando aspectos da saúde e bem-estar geral dos colaboradores. (MANCEBO; PEREIRA; LONGO, 2011).

Por QVT entende-se o bem-estar físico e mental dos trabalhadores das organizações. O termo abrange a satisfação com aspectos biológicos, psicológicos, sociais e organizacionais de acordo com os modelos mais contemporâneos. Esse entendimento aborda a preservação mental e física das pessoas, representada pela saúde ocupacional, segurança e ergonomia, além da busca do bem-estar, a satisfação e a motivação das pessoas, bem como a necessidade da avaliação da sua satisfação. $O$ atendimento desses requisitos é condição fundamental para que os trabalhadores contribuam para o resultado da organização, uma vez que a QVT afeta diretamente a vida dos indivíduos e consequentemente os resultados das organizações. (VITORIO et al., 2012).

\footnotetext{
${ }^{1}$ Artigo Científico apresentado a Faculdade do Vale do Jaguaribe - FVJ, Polo Mossoró, como exigência para obtenção do Certificado de Pós-Graduação em Gestão Estratégica de Pessoas e Liderança Organizacional.
} 
Os gestores das organizações devem se preocupar como está a QVT de seus colaboradores, utilizando estratégias para favorecer melhores condições de trabalho. Tal preocupação deve vir como uma tentativa de desenvolver novas atitudes às organizações e mudanças no modo de vida das pessoas, abrindo espaços para discussão e uma melhor qualidade de vida dentro e fora da mesma. Isso, por sua vez, como conseguinte, pode levar as organizações a alcançarem melhores resultados.

Alcançar os resultados desejados e necessários foi tema de preocupação entre as organizações, pois os resultados operacionais dependem em grande parte dos recursos humanos nas organizações. Logo, as práticas voltadas à melhoria da QVT impactam positivamente na produtividade. Dessa maneira, é de suma importância promover e preservar o bem-estar dos funcionários, buscando formas de satisfazer cada indivíduo para manter o nível de produtividade e uma qualidade de vida melhor.

É notável a necessidade da constante busca de qualidade nos serviços e satisfação de seus consumidores, na rede hoteleira da cidade de Mossoró/RN. E dessa maneira, o setor hoteleiro deve prover maneiras de manter um nível de qualidade em todos os seus setores e serviços. (COELHO, 2015).

Diante das considerações expostas, no presente trabalho se buscou complementar referências para o conhecimento em qualidade de vida no trabalho no setor hoteleiro local, investigando o entendimento que a rede mossoroense de hotéis concebia ao tema. Assim, como problema de pesquisa, estabeleceu-se: Qual a percepção dos gerentes do setor hoteleiro da cidade de Mossoró/RN em relação aos programas de QVT?

Diante disso, este estudo teve como objetivo geral analisar a percepção dos gerentes de dois hotéis do setor hoteleiro da cidade de Mossoró/RN em relação aos programas de QVT. Como objetivos específicos, procurou-se: investigar se as empresas possuíam programas de QVT e quais impactos estavam ocorrendo na satisfação do colaborador; e apreender a(s) lógica(s) dos discursos dos gerentes acerca da QVT como ferramenta de gestão dos recursos humanos.

Portanto, visando entender esta nova dinâmica ocupacional na cidade, em especial, alguns aspectos do trabalho local, no presente trabalho se buscou complementar referências para o conhecimento em qualidade de vida no trabalho no 
setor hoteleiro da localidade, investigando as percepções de dois gerentes de hotéis da cidade de Mossoró/RN.

\section{REFERENCIAL TEÓRICO}

Este tópico sintetiza a coleta realizada na literatura sobre o tema e se compõe em quatro subtópicos. No primeiro subtópico expõe-se acerca dos conceitos de QVT. Seguidos dos principais modelos e programas relacionados à QVT. Por fim, abordam-se os aspectos relacionados ao trabalho na hotelaria.

\subsection{CONCEITO DE QVT}

A QVT é um tema bastante amplo. Considerando a sua importância para o desempenho do indivíduo no ambiente de trabalho; e, por conseguinte, para o desenvolvimento das organizações; muitos especialistas e estudiosos despendem grande parte do seu tempo analisando os conceitos e teorias pertinentes ao assunto.

Segundo Limongi-França (1996, p. 143), a QVT pode ser entendida como “o conjunto das ações de uma empresa que envolve a implantação de melhorias e inovações gerenciais, tecnológicas e estruturais no ambiente de trabalho".

Por sua vez, Rocha (2007) conceitua QVT como a gestão dinâmica e contingencial de fatores físicos, tecnológicos e sociopsicológicos. Tais fatores afetam a cultura e renovam o clima organizacional, refletindo-se no bem estar do colaborador e na produtividade das organizações. Nesse sentido, a QVT deve ser considerada como uma gestão dinâmica porque as organizações e as pessoas mudam constantemente. E contingencial porque depende da realidade de cada organização no contexto em que está inserida

Para Chiavenato (2010), a QVT é uma teoria construída que envolve diversos fatores. Tais como: satisfação com o trabalho executado, as possibilidade de futuro na organização, o reconhecimento pelos resultados alcançados, o salário percebido, os benefícios auferidos, o relacionamento humano dentro da equipe e da organização, o ambiente psicológico e físico de trabalho, a liberdade de atuar e responsabilidade de 
tomar decisões e a possibilidade de estar engajado e de participar ativamente na organização.

Em complemento, Bruxel (2013) conceitua QVT como uma forma de pensamento envolvendo pessoas, trabalho e organização. Destacando dois pontos distintos: a preocupação com o bem-estar do trabalhador e com a eficiência organizacional; e, a participação dos trabalhadores nas decisões e problemas no ambiente laboral.

Em última análise, a QVT trata-se de um programa que visa facilitar e satisfazer as necessidades do colaborador durante o desenvolvimento de suas atividades no ambiente laboral. Tendo como aspecto principal, o fato de que a motivação das pessoas no trabalho está inteiramente ligada a sua satisfação com a organização. (RIBEIRO; SANTANA, 2015)

É possível perceber, conforme os autores citados, que, praticamente, todas as definições têm como ponto comum, propiciar o aumento do bem-estar dos colaboradores e uma maior participação dos colaboradores nas tomadas de decisões e problemas no ambiente laboral. De uma forma mais generalizada, a investigação da QVT deve preocupar-se com muitos fatores, destacando o salário; saúde e segurança no ambiente laboral e questões ergonômicas, que possam reduzir a probabilidade de contração de doenças ocupacionais e acidentes de trabalho. (LOONAT, 2013)

Pode-se compreender que ações que promovam a QVT são importantes não só do ponto de vista do colaborador, mais também da sociedade em geral. Permitindo assim, a satisfação dos colaboradores quanto as suas condições de trabalho, proporcionando benefícios a si mesmos e para a organização. Mas, para que isso aconteça, é preciso que essas ações sejam planejadas e implementadas de forma correta.

\subsection{MODELOS DE QVT}

Neste subtópico se expõe acerca dos principais modelos relacionados à QVT: Modelo de Walton (1973), Modelo de Westley (1979) e Modelo de Davis e Werthe (1983). 


\subsubsection{Modelo de Walton (1973)}

Ribeiro e Santana (2015) apresentam que o modelo de Walton estabeleceu alguns critérios básicos para que as organizações conseguissem avaliar a Qualidade de Vida dos trabalhadores que consiste em: compensação justa e adequada, condição de trabalho, uso e desenvolvimento de capacidades, oportunidade de crescimento e segurança, integração social na organização, constitucionalismo, trabalho e espaço total de vida, e relevância social da vida no trabalho.

Na mesma fonte consta que a compensação justa e adequada é a relação entre pagamento e condições de trabalho. A QVT levando em conta a remuneração salarial de acordo com a atividade executada pelo funcionário. Observa-se uma remuneração adequada, quando o salário encontra-se de acordo com o mercado e padrões aceitáveis pela sociedade. E compensação justa, quando o pagamento pelo trabalho realizado é compatível com as exigências e atividades executadas por cada cargo, comparando sempre com a média de pagamento de outras organizações.

Também se menciona na mesma fonte que a condição de trabalho aborda a jornada de trabalho, condições físicas e a segurança do colaborador em seu ambiente de trabalho. Nesse quesito avalia se as horas trabalhadas, horas extras, e o próprio ambiente físico do trabalho estão adequados. Evitando riscos de acidentes ou demais fatores que possam prejudicar a atuação do colaborador.

Ribeiro e Santana (2015) afirmam que o uso e desenvolvimento de capacidades referem-se ao desenvolvimento da capacidade humana dentro da organização. Desenvolver a autonomia do colaborador, desempenhar atividades que requeiram habilidades múltiplas e informações sobre o processo das atividades são fatores que possibilitam o desenvolvimento do colaborador.

Os autores também comentam que a oportunidade de crescimento e segurança diz respeito à oportunidade de crescimento do profissional dentro da organização. Através de uma promoção de cargo, cursos que enriqueçam seu currículo, programa de bonificação, valorização da carreira internamente, podendo aumentar salário. Essas oportunidades podem gerar segurança no emprego, visto que o colaborador reconhecerá o empenho da organização em fazê-lo crescer. 
A integração social na organização refere-se às relações interpessoais no ambiente de trabalho e à sua importância para um melhor desenvolvimento dos trabalhadores. Ausência de preconceitos e distinção entre trabalhadores, igualdade nos direitos e deveres, bons relacionamentos e pensamento coletivo contribuem para um ambiente melhor. (RIBEIRO; SANTANA, 2015)

Ribeiro e Santana (2015) observam que o constitucionalismo está relacionado ao cumprimento dos direitos e deveres dos trabalhadores, podendo ressaltar: privacidade, liberdade de expressão, tratamento imparcial e os direitos trabalhistas.

Ainda, comentam que o trabalho e o espaço total de vida abrangem a vivencia dos colaboradores na organização e em seu convívio família e social. Verificando se os mesmos refletem de forma positiva ou negativa na qualidade de vida de cada colaborador.

Por fim, a relevância social da vida no trabalho refere-se à responsabilidade social por parte da organização, ou seja, as consequências que ela traz para a sociedade. (RIBEIRO; SANTANA, 2015).

\subsubsection{Modelo de Westley (1979)}

O modelo de Westley aborda quatro categorias de problemas vivenciados pelos colaboradores no ambiente de trabalho: injustiça, insegurança, isolamento e anomia. Essas categorias são classificadas mediante a natureza do problema: fator econômico, fator político, fator psicológico e fator sociológico. (SILVA, 2015).

$\mathrm{Na}$ mesma fonte consta que a injustiça é caracterizada quando o colaborador se sente prejudicado dentro do trabalho. É um problema de natureza econômica, pois está relacionada às injustiças monetárias, à recompensa monetária pelo trabalho realizado.

Também consta que a insegurança é caracterizada pela instabilidade no trabalho devido à falta de políticas internas que dêem segurança ao colaborador. É um problema de natureza política, que também gera insatisfação, greve e sabotagem por parte dos trabalhadores.

Ainda, que o isolamento é caracterizado como o distanciamento do colaborador em seu grupo de trabalho, não havendo inter-relações com os colegas. Tem como natureza do problema os fatores psicológicos de cada colaborador. 
Por fim, a anomia, caracterizada pela falta de objetivos e perda de identidade, onde o colaborador se desinteressa pelo trabalho. É um problema de natureza sociológica, representado pelo conceito de participação ativa em decisões diretamente relacionadas com o processo de trabalho, com a forma de executar as tarefas e com a distribuição de responsabilidade dentro da equipe. (BRUXEL, 2013).

\subsubsection{Modelo de Davis e Werther (1983)}

O modelo proposto pelos autores Davis e Werther, classifica as exigências da natureza do cargo, visto que é o cargo que envolve mais intimamente o trabalhador. Assim, o modelo divide o cargo em três grupos de elementos: organizacionais, ambientais e comportamentais. (MEDEIROS, 2002).

Os elementos organizacionais referem-se à perfeita identificação da tarefa no cargo, ao estabelecimento de um fluxo coerente de trabalho e à adoção de métodos e processos que incorporem as práticas de trabalho para minimizar o tempo e o esforço do colaborador. Apesar de estes elementos conduzirem a especialização e a ciclos curtos de cargo, Davis e Werther consideram como positivo o fato de solicitarem pequenos investimentos em treinamento e permitirem rápido aprendizado, o que é adequado para trabalhadores de pouca experiência. (ROCHA, 2007)

Os elementos ambientais referem-se às condições externas a organização, as expectativas sociais, as habilidades e disponibilidades de empregados potenciais. Significando que o cargo não deverá ser muito complexo que obrigue a importação de colaboradores, e nem tão simples a ponto de gerar perturbação quando a mão de obra disponível for mais instruída. (ROCHA, 2007).

E por fim, os elementos comportamentais referem-se às necessidades de alto nível dos trabalhadores. Garantir que o projeto de cargo não vise apenas à eficiência, mas considere a autonomia do individuo, a responsabilidade pelo seu trabalho, o uso de variadas capacidades e habilidades no desempenho das atividades. Assim permite ao colaborador saber qual a repercussão de seu trabalho. (MEDEIROS, 2002).

É importante destacar-se que os modelos mencionados oferecem um referencial para a avaliação da satisfação dos colaboradores. Cada um enfatizando determinadas categorias e indicadores que influenciam na qualidade de vida destes em situação de trabalho. 


\subsection{PROGRAMAS DE QVT}

A QVT está relacionada a preocupações com o estresse e nas formas de evitá-lo, à busca de satisfação no trabalho, à importância da saúde mental e à necessidade de garanti-la no ambiente laboral. Sendo assim, os programas de QVT subsidiam atividades que favorecem a prevenção e a promoção da saúde. Atendendo as necessidades mais amplas do colaborador. Buscando conciliar o interesse dos colaboradores e da organização. (ANDRADE; VEIGA, 2012).

Para implementar um programa de QVT, deve ser feito um processo de diagnóstico organizacional e uma implementação cuidadosa, para que se obtenha um aumento da produtividade e da satisfação dos colaboradores. Além disso, a participação efetiva dos colaboradores nas decisões é um requisito essencial. (ANDRADE; VEIGA, 2012)

Para que um programa de QVT seja bem sucedido, existem três necessidades básicas. A primeira seria o desenvolvimento do projeto em níveis diferentes, coerentes e com o contexto em que será aplicado. O segundo envolve mudanças nos sistemas de gerenciamento e disposições organizacionais. E por fim são necessárias mudanças no comportamento do gerenciamento superior. É preciso que a gerência esteja comprometida com o processo para que este possa ser disseminado em toda a organização. (BUHLER; SILVA, 2010)

Para alcançar resultados satisfatórios com a implantação de um programa, é necessário o total comprometimento e preparação. Observa-se, então, que os programas de QVT não planejados e inadequados não levam aos objetivos desejados, tendo em vista que um programa de QVT necessita ser acompanhado.

Dessa maneira, é possível atribuir à preocupação devida como investir na qualidade da empresa, para que possa proporcionar condições de melhorias através de iniciativas que possibilitem estratégias para favorecer estas condições. As organizações e os colaboradores são a linha de frente do funcionamento e sucesso da atividade aplicada. (SOUZA, 2016) 


\subsection{TRABALHO NA HOTELARIA}

Ao longo do tempo o trabalho vem ocupando um espaço cada vez maior na vida das pessoas, passando a ser um elemento determinante no cotidiano de quem vive da venda de sua força de trabalho. Nesta perspectiva, a atividade profissional torna-se central na vida das pessoas. O homem passa a ocupar a maior parte do seu tempo em ambientes de trabalho, dedicando-se às atividades das empresas, as quais passam a fazer parte de sua representação enquanto sujeito.

Desta forma, os gestores das empresas do ramo hoteleiro percebem cada vez mais ser importante em suas atividades a participação do ser humano para garantir bons resultados (o chamado capital humano). Mas, para que se tenham resultados esperados, é preciso possibilitar cuidados aos funcionários. Assim, as organizações passam a proporcionar melhorias nas condições de trabalho, proporcionando um ambiente de melhor qualidade laboral aos indivíduos, mais propício ao seu bem-estar.

Alcançar os resultados desejados e necessários tem sido tema de preocupação entre os gestores, pois os resultados operacionais dependem em grande parte dos recursos humanos nas organizações. Logo, as práticas voltadas à melhoria da qualidade de vida no trabalho impactam positivamente na produtividade, através de um maior comprometimento e fidelidade a uma empresa por conta dos benefícios oferecidos por esta.

Dessa maneira, torna-se de suma importância preservar o bem-estar dos funcionários, buscando formas de satisfazer cada indivíduo para manter o nível de produtividade e uma qualidade de vida melhor.

Os gestores das empresas que prestam serviços hoteleiros estão cada vez mais exigentes com relação aos serviços oferecidos, sempre em busca de inovações. É um mercado bastante variado, tendo como característica a criação de produtos para os variados públicos, contendo uma complexidade nas suas atividades.

Passou-se a ver grandes aperfeiçoamentos no setor hoteleiro, mostrando e mantendo a qualidade dos serviços em virtude de garantir um bom nível por sentir-se a necessidade de uma melhor formação, no sentido de dar uma adaptação aos serviços modernos.

Diante de tantas pressões geradas pela competitividade no mercado de trabalho, conquistar a QVT é mais um desafio entre tantos outros enfrentados diariamente no 
ambiente de trabalho. Os profissionais devem buscar sempre novas alternativas que possam proporcionar um melhor bem-estar no ambiente de trabalho.

\section{PROCEDIMENTOS METODOLÓGICOS E RESULTADOS}

O presente trabalho caracterizou-se como pesquisa bibliográfica, pois se utilizou de consultas de livros e artigos, analisando conteúdos como base. Logo, o estudo foi realizado mediante natureza descritiva, procurando conhecimento sobre o assunto exposto.

A pesquisa de campo foi de caráter qualitativo, onde os dados foram coletados por meio de entrevistas realizadas em duas empresas do setor hoteleiro no ano de 2016. Desta forma, foram escolhidos os dois maiores hotéis da cidade de Mossoró, realizando a entrevista com a gerência dos respectivos estabelecimentos. A escolha dos hotéis deveu-se ao fato que ambos apresentavam alto padrão de qualidade, englobando diversos critérios de excelência, dentre os quais conforto e comodidade. As entrevistas foram realizadas no mês de março. De modo a garantir o anonimato das empresas, os hotéis foram identificados como Hotel 1 e Hotel 2.

\subsection{DISCURSOS DOS GERENTES ENTREVISTADOS ACERCA DA QVT}

A partir das informações coletadas através da pesquisa de campo, foi possível identificar não existir um consenso concernente ao termo Qualidade de Vida no Trabalho nos dois hotéis visitados. Contudo, de certa forma, percebeu-se a QVT como uma relação entre satisfação pessoal do funcionário, motivação pessoal e desempenho profissional:

A qualidade de vida no trabalho, a gente entende que, é quando o funcionário está satisfeito dentro da empresa, quando ele realiza suas atividades de certa forma feliz, quando veste a camisa da empresa. (INFORMANTE DO HOTEL 1).

Fazer com que o funcionário se sinta bem durante o seu turno de trabalho, a sua jornada de trabalho, fazer com que ele tenha além das obrigações, ele tenha pelo menos algum instante de lazer, onde ele possa descansar relaxar e conversar com os colegas. (INFORMANTE DO HOTEL 2). 
Percebeu-se surgirem sempre muitas ideias e conceitos sobre a QVT, podendose destacar, do ponto de vista das pessoas, a percepção de bem estar a partir das necessidades individuais e expectativas de vida.

Os dois entrevistados dos hotéis apontaram que sempre desenvolviam algum programa de qualidade de vida no trabalho a seus colaboradores, levando-se em conta que na busca pela melhoria viam a utilização da criação dos programas na sensibilização e reeducação de hábitos do trabalhador, e o próprio retorno que a empresa poderia ter, pois quando se tem um funcionário satisfeito atua com satisfação nas suas atividades. Os depoimentos descrevem a estruturação da QVT nos estabelecimentos:

\begin{abstract}
A nossa empresa ela desenvolve, a gente tem certificação de ISO 9001 e ISO 14000, é sistema de qualidade. Então quando a gente vai buscar toda essas atividades, em busca da ISO, a gente sempre envolve os colaboradores, quando possível envolve as famílias dos colaboradores pra que eles levem isso não só aqui na empresa, mas também pra sua casa. Então é isso que a gente se preocupa pra que ele tenha uma estrutura física em casa adequada, segura, pra que ele consiga estar no hotel bem, que ele consiga ir e vir bem, isso é uma preocupação nossa. (INFORMANTE DO HOTEL 1).

Atualmente depois que, faz pouco tempo que nós terceirizamos parte do hotel, houve algumas mudanças, ainda estamos nos readequando, mas nós temos alguns programas no hotel, temos a ginástica laboral, temos uma sala de convivência. Não temos agora porque o SESI está reestruturando, mas nós temos o EJA - Educação para Jovens e Adultos aqui dentro do hotel. Nós temos programas de treinamentos, não treinamento só para o desenvolvimento do trabalho em si, mas para a vida do profissional, o treinamento falando sobre saúde, sobre todo o assunto que se encontra e se encaixe e traz e aplica pra eles (INFORMANTE DO HOTEL 2).
\end{abstract}

Dessa maneira, foi possível atribuir à preocupação devida como investir na qualidade da empresa, para que possa proporcionar condições de melhorias através de iniciativas que possibilitem estratégias para favorecer estas condições. E na busca pela melhoria, vêem a utilização da criação de programas que colaborem na sensibilização e reeducação de hábitos do trabalhador.

Ao conceberem um programa de qualidade, perceberam que não seria implantado com sucesso se não houvesse um efetivo envolvimento e participação dos funcionários atuando com satisfação e motivação para a realização de suas atividades.

O hotel, como uma organização prestadora de serviço, está em contato direto com o hóspede e prioriza a qualidade dos serviços. Assim, a qualidade de vida direcionada ao funcionário é fundamental: “[...] O nosso funcionário tem que estar bem pra desenvolver seu trabalho, ele tem que estar bem para atender bem o cliente, então é 
essa a principal preocupação" (INFORMANTE DO HOTEL 1). A justificativa das empresas para o desenvolvimento de atividades de QVT se pauta no retorno de produtividade:

O retorno que a própria empresa tem, automaticamente quando um colaborador está bem, bem cursado, ele está bem ciente da sua função, no setor onde ele trabalha. Automaticamente isso repercute na empresa, a empresa como trabalha no turismo, as pessoas chegam e ele que então tem uma receptividade, dependendo da qualidade de vida de quem lhe está de frente ali sendo atendido. (INFORMANTE DO HOTEL 2).

Desta forma, foi visto que as empresas perceberam cada vez mais ser importante em suas atividades a participação do ser humano para garantir bons resultados (o chamado capital humano) e proporcionar um ambiente de melhor qualidade laboral ao indivíduo, na qual esteja propício ao seu bem estar. Logo, as práticas voltadas à melhoria da qualidade de vida no trabalho impactam positivamente nas atividades das empresas:

\begin{abstract}
Se a gente for pensar só no fator de empresa, a gente tem diminuição de atestado, diminuição de assistente de trabalho, as pessoas mais felizes aqui dentro, então a gente tem uma qualidade maior de satisfação das pessoas trabalhando conosco. A gente já foi eleita pelo segundo ano consecutivo uma das melhores empresas para os jovens começar a carreira, e a gente já está eleita acho pela $19^{\circ}$ vez uma das melhores empresas para se trabalhar. Eu acho que isso tudo é uma consequência do que a gente busca, que é que as pessoas estejam bem, ter uma política de crescimento dentro da empresa também, então às pessoas sempre são desafiadas a se desenvolver tanto dentro quanto for da empresa para buscar um cargo maior, uma qualidade de crescimento profissional. (INFORMANTE DO HOTEL 1).
\end{abstract}

As vantagens são imensas, porque primeiro as pessoas têm qualidade de vida, segundo a pessoa se qualifica, faz seu trabalho corretamente, presta serviços pra empresa corretamente, todo esse conjunto e essas pessoas trabalhando e tendo uma harmonia, isso faz cada vez mais a empresa crescer e repercutir nos nossos clientes, porque nossos clientes têm na internet a sua opinião sobre a empresa, e sempre está girando em torno de 8,0 ou 9,0 pontos de positivo em tudo, atendimento, em receptividade, em serviços a essas pessoas que a gente prioriza. A gente faz um trabalho de conscientização, de qualidade de vida, de salários, até a gente tem convênio com farmácia, com hospitais, então toda essa qualidade de vida que nós damos para o colaborador, repercute no tratamento da nossa empresa. (INFORMANTE DO HOTEL 2).

Apenas em um hotel foi verificado o acompanhamento das atividades, fazendo reuniões mensalmente, procurando saber a satisfação de cada colaborador e o que estava deixando a desejar. Para tanto, alguns aspectos da cultura organizacional ainda 
precisavam ser melhorados, para o hotel 1 o que dificultava era o volume de trabalho; para o hotel 2 não sabiam ao certo o que poderia ser melhorado.

As principais dificuldades que os gestores apontaram com relação à qualidade de vida no trabalho estiveram diretamente ligadas à relação colaborador-funcionário. Os depoimentos abaixo assim comprovam o argumento:

\begin{abstract}
As dificuldades que temos aqui é diretamente com o colaborador, a empresa faz um projeto, um curso em determinado lugar, como por exemplo, no SENAC ou em outro lugar, um curso de inglês para dar um aperfeiçoamento ao pessoal, e o pessoal não comparece, a gente fica muito triste com isso, a diretoria até acha que a gente perde tempo procurando certas coisas, mas a gente insiste, continua insistindo, sempre dá um curso de aperfeiçoamento, tem os cursos do próprio PPRA, os cursos que a gente faz anualmente com eles e a presença às vezes nos surpreende, às vezes são poucas presenças. A gente tem cursos de ergonomia, de tabagismo, curso de álcool, uso do álcool no ambiente de trabalho, prevenção de acidentes, doenças sexualmente transmissíveis, todos esses cursos são dados aos nossos colaboradores, agora ainda é difícil ter a presença maciça deles. (INFORMANTE DO HOTEL 1).

A maior dificuldade é às vezes até a própria desconfiança do funcionário, alguns não querem participar. Acho que a própria dificuldade é essa, porque a própria diretoria, gerência, eles tem essa consciência já, quando tem uma situação, por exemplo, dia das mães, vamos pensar alguma coisa, faz um esboço para a gerência geral, ele aprova, modifica alguma coisa, fazendo com que o funcionário participe. (INFORMANTE DO HOTEL 2).
\end{abstract}

Percebeu-se que as principais dificuldades foram com relação ao colaborador, pela falta de interesse para com os mesmos. Desta forma, a organização deveria passar a se preocupar em oferecer um ambiente que traga ao indivíduo conforto, segurança e bem estar, para que favoreça o uso de suas capacidades e, assim, obter maior eficiência na adoção de programas de QVT.

Com relação a uma boa condição de trabalho, os discursos apresentados foram referentes às ferramentas do trabalho, ter as condições de trabalhar. $\mathrm{E}$ o que o funcionário do hotel 1 destacou como satisfação no ambiente de trabalho, foi referente à relação de convívio com a equipe e os treinamentos que estavam sendo oferecidos.

Contudo, considera-se que uma empresa deve preocupar-se com a qualidade como um todo. De certa forma os hotéis priorizaram a qualidade dos serviços, mas como se apresentava para o funcionário. Os mesmos frisaram nos treinamentos, pois quando o colaborador chega ao ambiente será apresentado para vivenciar o ambiente laboral. 
É perceptível que a integração dos colaboradores das diferentes áreas e a comunicação aberta entre eles contribui para a qualidade do serviço, e como uma equipe, cada um ajuda com as atividades de competência, o que favorece o alcance do objetivo comum que é a qualidade no serviço.

Em suma, se pôde compreender a importância da qualidade de vida no trabalho, contribuindo para o desenvolvimento pessoal, a saúde e bem estar do funcionário. Considerou-se ter ficado evidente uma preocupação por parte da gerência dos referidos hotéis com relação à qualidade de vida de seus colaboradores, proporcionando atividades que satisfizessem o colaborador, destacando: comemorações, viagens, ações focadas no funcionário, no sentido de melhorar a cada instante. De certa forma uma política de estar sempre os valorizando.

Logo, percebeu-se que mesmo os informantes comunicando que existia QVT, não ia muito além de um discurso empresarial, às vezes modista, às vezes conveniente para o gestor afirmar positivamente. Mesmo assim, percebeu-se que o termo QVT estava em evidência mesmo sem a mesma estar estruturada de forma racional e planejada nas empresas pesquisadas.

\section{CONSIDERAÇÕES FINAIS}

Para analisar a qualidade de vida no trabalho na rede hoteleira de Mossoró/RN, foi realizada uma pesquisa para levantar os indicadores da QVT, na qual se pôde compreender a importância e contribuição para o desenvolvimento pessoal e bem estar do colaborador.

É um tema de crescente importância no mundo do trabalho, tendo por base a percepção dos trabalhadores em relação a diversos fatores que interferem nas condições e relações de trabalho. A necessidade de QVT vem se tornando cada vez mais explícita nas organizações, podendo possibilitar ao trabalhador conviver em um ambiente que lhe proporcione satisfação e o motive a trabalhar, na tentativa de oferecer melhorias ao bem-estar das pessoas, se tornando uma moderna estratégia empresarial.

O objetivo da pesquisa aqui apresentada foi analisar a percepção dos gerentes do setor hoteleiro da cidade de Mossoró/RN em relação aos programas de QVT. Como conclusão, inferiu-se existir certa preocupação por parte da gerência dos hotéis 
escolhidos de investir na qualidade de vida de seus funcionários, buscando melhorias nas condições e nas relações de trabalho. Todavia, mesmo os informantes comunicando que existia QVT, não estavam muito além de um discurso empresarial, às vezes conveniente para o gestor afirmar positivamente.

Percebeu-se, pois, existirem medidas pontuais pautadas em tentativas de favorecer o colaborador, mas sem aplicação de nenhum modelo de QVT. A qualidade de vida no trabalho ficando a mercê da intuição gerencial. Mesmo assim, percebeu-se que o termo QVT esteve em evidência, mesmo sem a mesma estar estruturada de forma racional e planejada nas empresas pesquisadas.

Os resultados dessa pesquisa mostraram ser importante ter uma boa condição de trabalho, ter as ferramentas e condições de trabalhar, já que é importante sensibilizar o bem estar dos colaboradores. Isto contribui na obtenção de maior eficiência no desenvolvimento da organização como um todo.

Notou-se a importância de diversos conceitos em busca de melhores modelos que se enquadrassem em cada empresa, já que estavam vivendo em um ambiente competitivo, e a busca por resultados torna-se cada vez mais desafiadora. Dentre as atividades desenvolvidas, verificou-se ocorrer ginástica laboral, período de descanso dentro da rotina do trabalho, lazer em grupos, plano de saúde e outros.

A partir dos resultados apresentados, sugere-se, às organizações, a adoção de um programa de QVT formal, tornando-se necessário que seja mencionado um modelo que sirva como referencial para a implantação do programa, que se adapte a cada situação.

Para finalizar, ressalta-se a relevância da participação e disponibilidade, por parte da gerência dos referidos hotéis escolhidos para este estudo. Visando contribuir para a diminuição da insatisfação no ambiente de trabalho, no qual se tenderá a aumentar suas contribuições e elevar o nível de interesse que representa um alto custo para a organização.

\section{REFERÊNCIAS}

ANDRADE, P. P.; VEIGA, H. M. da S. Avaliação dos trabalhadores acerca de um programa de qualidade de vida no trabalho: validação de escala e análise qualitativa. Revista Psicologia: Ciência e Profissão, Brasília, v. 32, n. 2, p. 304319. Jan. 2012. 
BRUXEL, C. A qualidade de vida no trabalho (QVT) - em uma organização hospitalar de Ijuí-RS. 2013. 66 f. Monografia (Curso de Graduação em Administração) - Departamento de Ciências Administrativas, Contábeis, Econômicas e da Comunicação. Universidade Regional do Noroeste do Estado do Rio Grande do Sul, Ijuí, 2013.

BUHLE, L. V; SILVA, N. M. B. da. Qualidade de Vida no trabalho: contribuições para o desenvolvimento de trabalhadores e sua repercussão nas organizações. In: GT-08 MEIOS DE HOSPEDAGEM EM TURISMO DO VI SEMINTUR, 2010, Caxias do Sul. Anais... Caxias do Sul: UCS, 2010. p. 5.

CHIAVEnAto, I. Gestão de Pessoas: o novo papel dos recursos humanos nas organizações. 3. ed. Rio de Janeiro: Elsevier, 2010.

COELHO, É. A. Qualidade de vida no trabalho e seu reflexo na qualidade de vida pessoal: o caso do trabalho feminino no setor hoteleiro de Viçosa-MG. 2015. $161 \mathrm{f}$. Dissertação (Mestrado em Economia Doméstica)-Departamento de Economia Doméstica. Universidade Federal de Viçosa, Viçosa, 2015.

LIMONGI-FRANÇA, A. C. Indicadores Empresariais de Qualidade de Vida no Trabalho esforço empresarial e satisfação dos empregados no ambiente de manufatura com certificação ISO 9000. Tese (Doutorado em Administração) Faculdade de Economia, Administração e Contabilidade - FEA (USP), São Paulo, 1996.

LOONAT, S. Qualidade de vida no trabalho de profissionais do sector de consultoria da cidade de Maputo. 2013. 76 f. Monografia (Licenciada em Psicologia Organizacional) - Escola Superior de Gestão, Ciências e Tecnologias da Universidade Politécnica, Maputo, 2013.

MANCEBO, E.; PEREIRA, L.; LONGO, O. Qualidade de vida no trabalho: perspectivas do setor hoteleiro da cidade do Rio de Janeiro. Tourism\& Management Studies, Algarve, Extra 1 (ProceedingsInternationalConferenceTourism\& Management Studies 2011: FullPapers), 2011, p. 683-691.

MEDEIROS, E. G. Análise da qualidade de vida no trabalho: um estudo de caso na área da construção civil. 2002. 137 f. Dissertação (Mestrado em administração)-Escola de Administração. Universidade Federal do Rio Grande do Sul, Porto Alegre, 2002.

RIBEIRO, L. A; SANTANA, L. C. Qualidade de vida no trabalho: fator decisivo para o sucesso organizacional. Revista de Iniciação Científica - RIC, Cairu, v. 2, n. 2, p. 7596, Jun. 2015.

ROCHA, R. F. A qualidade de vida no trabalho em pequenas empresas: a mensuração rumo à melhoria - o caso agromídia software ltda. 2007. 136 f. Monografia (Curso de Secretariado Executivo Trilíngue)-Departamento de Letras. Universidade Federal de Viçosa, Viçosa, 2007. 
SILVA, A. P. P. D. Relação entre o perfil sócio demográfico e a qualidade de vida no trabalho dos servidores técnicos administrativos da ufersa. 2015. $69 \mathrm{f}$. Monografia (Curso de Graduação em Administração) - Departamento de agrotecnologia e Ciências Sociais. Universidade Federal Rural do Semiárido, Mossoró, 2015.

SOUZA, D. de. O trabalho no turismo como temática nos periódicos científicos associados aos programas Stricto Sensu em Turismo no Brasil. Revista Turismo e Sociedade, Curitiba, v. 9, n. 1, p. 1-20, janeiro-abril de 2016.

VITORIO, D. M; BORGES, U. da N; SOUSA, C. S. G. de; VILAR, B. L; SILVA, V. P. da. A qualidade de vida no trabalho: estudo de caso no setor hoteleiro em Campina Grande na Paraíba. In: ENCONTRO NACIONAL DE ENGENHARIA DE PRODUCAO, 32, 2012, Bento Gonçalves. Anais... Bento Gonçalves: ABEPRO, 2012, p. 1-9.

Recebido em: 12-04-2018.

Aprovado em: 12-05-2018.

Versão finalizada em: 06-12-2018. 